See discussions, stats, and author profiles for this publication at: https://www.researchgate.net/publication/327426317

\title{
Subject pronoun expression and language mode in bilingual Spanish
}

Article in Studies in Hispanic and Lusophone Linguistics · September 2018

DOI: 10.1515/shll-2018-0010

1 author:

Ana De Prada Pérez

National University of Ireland, Maynooth

16 PUBLICATIONS 62 CITATIONS

SEE PROFILE 


\title{
Ana de Prada Pérez* \\ Subject pronoun expression and language mode in bilingual Spanish
}

\author{
https://doi.org/10.1515/shll-2018-0010
}

\begin{abstract}
In research on Spanish subject pronoun expression, Spanish-English bilinguals have been shown to present higher rates of expressed subjects in code-switching than in monolingual Spanish mode, an outcome attributed to perseveration from English or to convergence with English. In this study we seek to arbitrate between these competing accounts. For that purpose, productions were elicited from bilinguals in an oral elicitation task, manipulating perseveration source and target structures in three modes: monolingual Spanish, language switching, and code-switching. Participants demonstrated the anticipated sensitivity to perseveration across conditions and effects of bilingual mode in the code-switching condition, with greater expressed pronoun use with omitted subject primes. These results allow us to isolate structural perseveration from bilingual effects and to ascribe the source of increased use of expressed pronominal subjects in bilingual Spanish to dual language activation or convergence.
\end{abstract}

Keywords: subject expression, structural persistence, syntactic perseveration, priming, code-switching, bilingual mode

\section{Introduction}

This research article concerns itself with the effect of language mode (Grosjean 1998, 2001) on the production of variable phenomena in bilingual speech. The particular phenomenon under study is subject pronoun expression (SPE) in the Spanish of U.S. Spanish-English bilinguals. In Spanish, a null subject language, the distribution of expressed vs. omitted ${ }^{1}$ personal pronominal subjects is regulated by a cluster of variables, among these are:

\footnotetext{
1 In the generativist tradition these forms are also referred to as omitted and expressed pronominal subjects. Refer to Otheguy (2015) for arguments against the use of this terminology in variationist linguistics.
}

*Corresponding author: Ana de Prada Pérez, Maynooth University, Maynooth, Ireland, E-mail: Ana.DePradaPerez@mu.ie 
discourse function, co-referentiality (switch reference), and person, to name but a few. Additionally, it is generally accepted that expressed forms lead to expressed forms, and, questionably, omitted forms lead to omitted forms, across genres and dialects of Spanish (cf. Cameron 1994; Travis 2005, 2007; however see Otheguy 2015), a tendency that has been referred to as priming or structural persistence or perseveration. Otheguy (2015) clarifies that priming is the name of the cognitive-based explanation for the distribution, which is better referred to as perseveration or persistence, terminology that we adopt here.

Particularly relevant to this project is the examination of Spanish SPE in code-switching (CS), in which bilinguals use both languages and alternate between them. While previous research on CS has largely centered on the syntactic restrictions on CS, giving rise to highly debated theories (cf. MacSwan 1999; Muysken 2000; Myers-Scotton 1993), a distinct line of research has focused on the consequences of CS for variable phenomena. Toribio (2004) and Torres-Cacoullos and Travis (2011, 2016) offer data where Spanish-English bilingual speakers use expressed pronominal subjects at a higher rate in CS than in monolingual modes. This result, however, is differentially explained in these two papers. While Toribio (2004) interprets it as indicative of convergence of the two contributing systems, Torres-Cacoullos and Travis $(2011,2016)$ conclude that such elevated rates in their own data are due to structural perseveration from previous instances of English and Spanish expressed subjects, not necessarily to CS. Torres-Cacoullos and Travis (2016), thus, try to arbitrate between the convergence-via-codeswitching hypothesis (exemplified here by Toribio's 2004 work) and the contextual distribution-via-codeswitching hypothesis (proposed by Torres-Cacoullos and Travis 2016). Both accounts acknowledge the effect of perseveration within and across languages but only Toribio (2004) identifies a CS effect independent of structural perseveration. Although Torres-Cacoullos and Travis (2016) convincingly argue in a methodologically sound analysis of their corpus for the contextual distribution-via-codeswitching hypothesis, the contradictory results between Toribio's and Torres-Cacoullos and Travis' (2016) analyses merits further scrutiny. One possible difference across these studies is the person examined (only 1sg in Torres-Cacoullos and Travis 2011, 2016; 3sg in Toribio's fairy tale narratives) as well as their definition of CS contexts. This paper aims to contribute to the debate on the source of the increased use of expressed pronominal subjects in Spanish-English CS with a study in which perseveration and language mode are manipulated in the design and where the elicited verb forms are $3 \mathrm{sg}$. 
The present research pursues this line of inquiry, assessing the effects of mode on SPE in bilinguals' Spanish-language production across monolingual mode and two bilingual modes: CS and language switching (LS). LS consists of switching that occurs across speakers (e.g., one speaker asks in English and the other responds in Spanish) while we use CS in contexts of intra-speaker switching. Consistent with antecedent literature, we anticipate perseveration effects or structural persistence across all modes; the issue is whether the effects of English are enhanced in the bilingual modes, where Spanish and English are simultaneously deployed. While it is generally accepted in the psycholinguistic literature that both languages are active even when bilinguals are in monolingual mode (Kroll Judith et al. 2005 and references therein), our assumption here is that the activation level is higher when bilinguals are in bilingual mode (Green 1986). In pursuing these issues, the work complements the methods of variationist sociolinguistics, contributing to the investigation of persistence of syntactic structures in three ways: it examines perseveration in subject expression in Spanish, which has been amply explored but without benefit of task designs that control for linguistic context; it investigates SPE across monolingual and bilingual modes, analyzing speech samples from participants in a Spanish-only condition, an English-Spanish LS condition, and a Spanish-English CS condition; and it focuses on a group of bilinguals that remains underrepresented in studies of syntactic perseveration: U.S. Spanish heritage bilinguals. The study also furnishes new data and methods to the body of knowledge on variable subject expression in Spanish, by attending to third person singular lexical and pronominal forms (which are woefully understudied relative to first person singular forms), by isolating the potential contributions of perseveration through controlled tasks, and by examining the role of dual language activation in LS and CS on subject expression.

The remainder of the article is organized as follows. Section 2 provides a review of research on structural perseveration from the fields of psycholinguistics and sociolinguistics as well as works on SPE in Spanish, both in the variationist literature and the bilingualism literature. Summarizing the advances in these areas and taking account of some of the limitations, Section 3 provides the rationale for the present undertaking; its main purpose is to set out the research questions and the hypotheses, motivate the research design, and present the results. Section 4 discusses and contextualizes the results, and finally, Section 5 offers conclusions and avenues for research on variable phenomena that avail themselves of tools and techniques from allied fields. 


\section{Previous studies: subject expression, structural perseveration, and bilingual code-switching}

As the present study examines Spanish SPE in monolingual and bilingual Spanish, the following sections review relevant findings on structural perseveration of subject expression vs. omission in monolingual Spanish, structural perseveration within and across languages, and structural perseveration of subject expression vs. omission in bilingual SpanishEnglish mixed speech.

\subsection{Subject expression in Spanish}

Variationist studies of Spanish SPE provide ample evidence that the distribution of subject pronoun expression vs. omission is variable and orderly. One of the variables that has received considerable attention in variationist research is connectivity in the speech, where by the more connected the speech is the more probable it is that a speaker will use an omitted form (Otheguy et al. 2007). The examples in (1) show the decrease in speech connectivity that has been associated with the use of a higher rate of expressed pronominal subjects in Spanish.

(1) a. Same referent and same TAM

Y yo los bañaba, y los vestía, les daba de comer, los ponía a dormir.

'And I would bathe them, dress them, feed them, put them to sleep.' (Travis 2007)

b. Same referent but different TAM

Mañana voy. Yo dejé diez paquetes allá.

'I will go tomorrow. I left ten packets there.' (Travis 2007)

c. Different referent

Parece que ellos piensan que es signo de cultura.

'It seems as if they think that is it a sign of culture.' (Morales 1997)

In (1a) both the referent ( $y o$ 'I') and the TAM (imperfect indicative) are constant, which has been reported to favor omitted subjects. In (1b) there is the same referent ( $y$ o 'I') in both clauses but the TAM changes from the present indicative in the first sentence to the preterit in the second sentence, which has been shown to neither favor nor disfavor expressed pronominal subjects. Lastly (1c) exemplifies more disconnect between the two clauses as 
the subject of the first clause is different from that of the second clause, a context where expressed subjects tend to be produced more. Other significant factors examined across studies are verb person, with first person found to increase the odds of using an expressed pronominal subject (Enríquez 1984; Morales 1997; Otheguy et al. 2007; Silva-Corvalán 1982, 1994), verb form ambiguity, which is also shown to increase the probability of using an expressed form (Silva-Corvalán 1994; although see Casanova Seuma 1999; Morales 1997; Ranson 1991), and semantic verb type, where mental and stative verbs favor the use of the expressed form more than external activities (Enríquez 1984; Morales 1997; Otheguy et al. 2007; Otheguy and Zentella 2012; Silva-Corvalán 1982, 1994; Travis 2007), among other factors.

In addition to language-internal variables, some community or individual factors have received attention in the extant literature on Spanish subject pronoun expression. Especially relevant are studies that examine the effect of language contact, particularly the contact situation between a language that allows omitted subjects and a language that does not. These studies employ variationist comparative methods where the speech from bilinguals who have experienced different degrees of contact with English (e.g., monolingual Spanish speakers vs. newcomers vs. US-born and raised) is analyzed to evaluate the possible increase in expressed subject rates and the changes in factors regulating their distribution as an index of degree of contact with English. These studies return conflicting results: there are those that report a bilingual effect, mostly from the Otheguy and Zentella (2012) corpus (Lapidus and Otheguy 2005a, 2005b; Otheguy et al. 2007; Otheguy and Zentella 2012; Shin 2013; Shin and Otheguy 2013; among others) and those that do not (Torres Cacoullos and Travis 2010). It is possible, though, that the contradictory results are due to different grammatical persons included in the studies; some studies only examine first person and others third person or all persons. Prada Pérez and Gómez Soler (forthcoming) show evidence of language contact effect only in 3sg in Spanish-English heritage speakers (HSs). In cases where a bilingual effect has been reported, some researchers have sought to attribute it to perseveration from English, a hypothesis we consider in the following section.

\subsection{Structural perseveration or syntactic persistence or structural perseveration}

In her seminal study, Bock (1986) found that the structure of a prime sentence persists into succeeding sentences in oral production. Subsequent studies 
confirm the pervasiveness of structural persistence, observed via a variety of tasks, targeting several different structures, and focusing on multiple languages. More importantly for the present purposes, results from a variety of studies have helped to consolidate the notion of structural perseveration as a mechanism that operates not only within but across languages. The most studied construction in both monolingual and multilingual experiments has been the double-object dative, illustrated in the following Spanish-English example from Meijer and Fox Tree (2003).

\section{(2) a. Spanish Prime: V DP PP}

La mujer le trajo $[e l \text { niño }]_{D P}[a \text { su mamá }]_{P P}$ the woman dat.3p.sg. brought the child to her mom 'The woman brought the child to her mom.'

\section{b. English Response: V DP PP}

The car salesman sold [a red sports car $]_{\mathrm{DP}}$ [to the woman $]_{\mathrm{PP}}$

\section{c. Target: V DP DP}

The car salesman sold [the woman $]_{\mathrm{DP}}$ [a red sports car $]_{\mathrm{DP}}$

As can be surmised from the example, the Spanish DP-PP construction (2a) primes the counterpart construction in English (2b), over the more frequently used DP-DP target (2c). In another study, Hartsuiker et al. (2004) found perseveration of grammatical voice as Spanish-English bilingual participants described pictures to one another while switching languages; Spanish passives primed the production of passive sentences in English.

Structural perseveration has also been observed in variationist sociolinguistic studies, in both monolingual and bilingual spoken language corpora. Regarding monolingual studies, Judith and Labov (1983) were the first to uncover structural perseveration effects in passive vs. active constructions in English. For Spanish and Brazilian Portuguese, researchers have examined perseveration effects in various morphosyntactic structures, among these, nominal number agreement (Scherre and Marta 2001) and word order (Raña Risso 2010), but the overwhelming majority of studies focuses on pronominal subject expression, using different elicitation techniques. A number of researchers analyze the omission and expression of 1st person singular subject pronouns, sometimes in addition to other grammatical persons, drawing on interview narratives collected in different communities, e.g., in San Juan and Madrid (Cameron 1995), New York City (Flores-Ferrán 2007), Colombia (Travis 2005, 2007), and New Mexico (Travis 2007). The idea behind these studies is that "pronouns lead to pronouns and omitted subjects lead to omitted subjects" (Cameron 1994: 40), in what Travis (2005) aptly labels the 'yo-yo' effect, even 
across conversational turns. This is illustrated in examples (3) and (4), from Cameron and Flores-Ferrán (2004), Travis (2005), and Travis (2007), respectively.

(3) ...Yo soy un títere de la calle. No me cruces la línea a mí. Y al tipo empujarme, yo le metí un puño en la misma oficina. Y el otro salió corriendo. $Y$ entonces la secretaria estaba mirando pero se dio cuenta que fue que él me empujó. Yo me defendí. ¿Entiendes?....

'... I am a street guy. (You) don't cross my line. And the guy, when he pushed me, I punched him right in the office. And the other guy ran out. And then the secretary was looking but she realized that he had pushed me. I defended myself. Understand?' (Cameron and Flores-Ferrán 2004: 52)

(4) Ahí, Ø tengo uno, Ø tengo dizque el capa, ahora, y Ø tengo que bajar el Macafi por internet, $y$ sinceramente, $\emptyset$ no he tenido tiempo.

'(I) have one, (I) have one so-called capa now, and (I) have to download MacAfee over the internet, and honestly, (I) haven't had the time.' (Travis 2005: 330)

As the examples illustrate, subject pronouns are most likely to be produced following an explicit mention of that same pronominal subject, and subject omission is most likely found after a prior unexpressed subject, across interview narratives and conversational genres. Otheguy (2015), however, examines perseveration in a sample of the Otheguy and Zentella (2012) corpus and only reports priming effects from expressed subjects.

As stated, the expression vs. omission of Spanish personal pronouns is the most examined structure in the variationist sociolinguistic perseveration literature, and, 1st person singular subject expression appears to be the focus of the majority of studies.

\subsection{The effects of code-switching on spanish morphosyntax}

In addition to studying certain morphosyntactic features in U.S. Spanish, some researchers in the field of bilingualism and language contact have used similar research methods to examine code-switching (CS), broadly defined as the linguistic phenomenon in which speakers employ two or more languages in the same utterance, either within or across sentences. Unlike antecedent research that aimed to understand the 'grammar' of CS by reference to extant theoretical constructs (e.g., the Government Constraint of DiSciullo et al. 1986; the 
Functional Head Constraint of Belazi etal. 1994, and the null theories of Mahootian 1993; MacSwan 1999), this new approach consists of examining CS as an independent variable, exploring its effects on certain linguistic phenomena. For instance, researchers have reported reflexes of CS on segmental features such as VOT (Balukas and Koops 2014; Bullock et al. 2006; Bullock and Toribio 2009; Olson 2013; Piccini and Arvaniti 2015) and suprasegmental properties such as pitch height and stressed vowel duration (Olson 2012, 2015). In the realm of morphosyntax, a CS effect has been reported for copula distinction among Spanish-English bilinguals (see Prada Pérez and Hernández 2017).

Such an approach has been employed for the study of SPE, too. Toribio (2004) analyzed the speech samples of two Mexican-American Spanish-English bilinguals as they produce fairy tale narratives in Spanish and in SpanishEnglish CS, inviting independent judges to assess the appropriateness of the expressed pronominal subjects in the segments identified as Spanish. The results showed that seemingly infelicitous expressed pronouns were produced more often when the participants were producing CS narratives, as in (6a) than in monolingual Spanish narratives, as in (6b).

(6) a. ... all the things that, that, that she took for granted, you know, she, uh, she started to reflect upon, así que ella decidió en la, durante la cuarta semana, de que ella se iba a regresar al palacio, ella no podía vivir como una persona humilde.

'... so she decided in the, during the fourth week that she was going to return to the palace, she could not live like a humble person.' (Toribio 2004: 171)

b. ... el lobo, el mismo lobo que la iba persiguiendo. Él le dio unas flores y le dijo qué bonita Ø se miraba. También Ø le preguntó que pa’ dónde Ø iba, verdad, y ella le respondió, y le dijo, “Ø voy a la casa de mi abuelita...”. '... the wolf, the same wolf that had been following her. He gave her some flowers and told her how pretty (she) looked. (He) also asked her where (she) was going, right, and she responded and she said, "(I) am going to my grandmother's house...”.' (Toribio 2004: 170)

Toribio interprets these findings as reflecting the enhancement of cross-linguistic similarity -i.e., convergence of Spanish with English - in CS, following Bullock and Toribio (2004). The idea that convergence is enhanced in CS, or the convergence-via-codeswitching hypothesis, is not novel. Gumperz and Wilson (1971), and more recently Backus (2004), Gardner-Chloros and Edwards (2004), Myers-Scotton (2002), Sebba (1998), and Thomason (2001), hypothesize that convergence between the contact languages is likely to be enhanced when language systems 
are simultaneously activated (convergence-via-codeswitching hypothesis), as when bilinguals engage in CS.

Torres-Cacoullos and Travis (2011) set out to test Toribio's hypothesis by examining the rates and constraints of SPE using a variationist approach to the analysis of spontaneous data. Specifically, the authors compared the segments of speech where bilinguals had recently (with the previous 3 clauses or 10 Intonational Units) employed English to those where they had not used English. While the use of expressed pronominal subjects was higher in the 'CS' than in the monolingual condition, the difference did not reach significance when all the participants were included. In an analysis where only those speakers who regularly engage in CS were included there was a significantly higher rate of expressed pronominal subjects in CS than in the monolingual condition. To further explore differences, the results from two logistic regressions, one for the data with CS and one with the monolingual mode data, were compared. No differences were found between the CS and non-CS data with respect to the constraints that regulate the use of expressed pronominal subjects. They report that perseveration in CS could come from the Spanish subject and the English subject form 'I', which increased the contexts of a previous expressed subject. In particular, 63\% of the data had an unexpressed previous subject in the monolingual mode contexts while it was only $43 \%$ in the CS contexts. Therefore, the authors argue that the increase in subject expression in the CS condition is due to contextual distribution, such that the higher rate in CS is due to perseveration from a preceding expressed subject, either the Spanish pronoun yo or the English pronoun I.

The divergent interpretations of the increase in expressed pronominal subjects in Toribio (2004) and Torres-Cacoullos and Travis (2011) call for consideration. First, there are discrepancies as to what constitutes CS. Toribio (2004) refers to CS as "when bilinguals' languages are simultaneously deployed" and explains that it includes alternation and insertion (Muysken 2000). The contexts selected as CS in Torres-Cacoullos and Travis (2011), on the other hand, include recent use of English, and not necessarily intra-sentential and/or inter-sentential change of linguistic codes. To address this difference, Torres-Cacoullos and Travis (2016) explore a different sample from the same corpus separating contexts of more immediate CS and those with less immediate CS. The conclusion remains the same in contexts of more immediate CS: the higher rate of overt pronominal subjects is attributed to intra-language perseveration and to a slightly lesser degree to cross-linguistic perseveration. Thus, the results in Toribio (2004) could also be attributed to perseveration, an issue that cannot be resolved without coding for form of the previous mention. Moreover, the data points differ, and hence the analyses are not comparable. In particular 
Torres-Cacoullos and Travis (2016) analyze 1sg subjects and Toribio's (2004) examines 3sg. As expressed above, studies on the effects of English language contact on subject expression in Spanish have returned contradicting results. Although these results could be attributed to communities being different, they also include different persons in their analysis. Crucially, those that focus on 1sg are the studies that tend not to report an effect. In Prada Pérez and Gómez Soler (forthcoming), effects of English language contact were reported only for 3sg in the speech of Spanish heritage speakers. Similar results have been reported for Spanish L2ers (Geeslin and Gudmestad 2016; Gudmestad et al. 2013). Thus, with Toribio's (2004) data not being coded for perseveration and including 3sg subjects, it remains a question whether we find CS effects independent of perseveration in 3 sg subject pronoun expression, the crucial issue that we explore here.

To summarize, the crucial difference between the previous two accounts is not whether perseveration is a factor or not in subject expression in SpanishEnglish CS, as both assume it has an effect, but whether in addition to perseveration there is an independent CS effect, which is the core research question in this paper. In order to appropriately test the convergence-via-codeswitching hypothesis, then, it is necessary that participants be engaged in CS and that the perseveration form be manipulated in the design. The purpose of this study, then, is to shed some light on the contribution of perseveration vs. CS to the increased use of expressed pronominal subjects in bilingual vs. monolingual utterances by controlling perseveration in the comparison of monolingual vs. bilingual production by the same group of speakers.

In concluding this overview of the literature, it merits pointing out that the subject perseveration studies carried out by Toribio (2004) and Torres-Cacoullos and Travis $(2011,2016)$ differ in important respects from the psycholinguistic studies of structural perseveration reviewed above. While all of these studies consider the consequences of activating two linguistic systems on particular linguistic phenomena, the psycholinguistic studies rely on data elicited via language switching (LS), understood as experimentally cued switching, whereas the studies of structural perseveration in bilingual speech are based on CS data typically collected in spontaneous conversation. LS and CS may represent distinct degrees of activation or language modes (Grosjean 1998, 2001). Thus, it could prove informative to examine the consequences of each type of bilingual mode for perseveration. The experimental design of the study detailed below includes modes that represent degrees of linguistic activation found among bilingual speakers: monolingual mode, in which one language is employed while the other remains relatively inactive, and two bilingual modes - LS and CS. 


\section{The present study}

The important advances in the previous literature have inspired and informed our study both in topic and methodology. As in previous variationist studies, we are interested in the effect of perseveration on SPE in Spanish; these studies employ logistic regressions on subject pronoun use in spontaneous data production taking into account the form of the previous subject as a variable. In the present study, we elicit production data where we provide the previous subject and, thus, are able to control for it. Thus, we also draw on techniques from laboratory studies by carefully controlling context and adopting and adapting the language-switching paradigm of perseveration studies. In so doing, we bring new methods and data to variationist research on subject expression in Spanish, with the purpose of clarifying whether the increased use of expressed pronominal subjects observed in CS can be attributed to the contextual distribution-via-codeswitching hypothesis, or perseveration from the presence of English as well as Spanish expressed subjects in the preceding context (Torres-Cacoullos and Travis 2011, 2016) or if it can be attributed to the convergence-via-codeswitching hypothesis, or an effect of language mode (Toribio 2004). We seek to adjudicate between these hypotheses by eliciting oral data in controlled linguistic contexts.

\subsection{Research questions and hypotheses}

As noted, previous research in psycholinguistics indicates that the use of a specific form of variable structural phenomena increases the probability of its subsequent use, as opposed to other available forms, in controlled monolingual and LS trials. Likewise, previous literature examining naturalistic data has reported a higher use of expressed pronominal subjects in Spanish when bilinguals are CS than when they are in monolingual mode. In the sociolinguistics literature, the use of expressed pronominal subjects is found to lead to a higher probability of pronoun use; likewise, omitted subjects are variably found to lead to more omitted subjects (Otheguy 2015). Pursuing this line of inquiry, we seek to answer the following question regarding perseveration in subject expression across conditions that represent monolingual and bilingual language modes:

- Research Question 1

- Is there evidence of intra- and cross-linguistic perseveration of subjects (omitted, expressed pronominal, and lexical subjects) in bilinguals' Spanish productions in Spanish monolingual mode and bilingual (LS and CS) modes? 
In view of previous findings where both intra- and cross-linguistic perseveration of subjects have been attested, we anticipate that participants will show evidence of intra-linguistic perseveration in the Spanish monolingual mode condition in the form of higher rates of expressed pronouns and lexical subjects in contexts where they are primed with expressed pronouns and lexical subjects and possibly higher rates of omitted subjects in contexts where they are primed with omitted subjects. Similarly, we expect to find evidence of cross-linguistic perseveration in the bilingual (LS and CS) conditions for lexical and expressed subject pronouns. In the LS condition, English pronouns and lexical subjects in prompts are expected to lead to more Spanish expressed pronominal subjects and lexical subjects in responses. In the CS condition, we hypothesize that English and Spanish expressed pronominal subjects and lexical subjects will lead to more Spanish expressed pronouns and lexical subjects, and Spanish omitted subjects will possibly lead to more Spanish omitted subjects.

Since perseveration relies on the accessibility of a linguistic form after being activated, it is not surprising that cross-linguistic perseveration takes place. In the psycholinguistic literature there is a wealth of research that examines the activation of both languages in the mind of a bilingual speaker. Despite the initial controversy over the possible complete deactivation of one language while the other is in use (what is known as "monolingual mode"), most researchers today agree that none of the composite languages of a bilingual can be completely "turned off"; rather, they remain active to different degrees even when speakers are operating in monolingual mode (see Kroll Judith et al. 2005, for a review). In this study we are interested in the effect that the degree of activation of the less active language has on the pervasiveness of structural perseveration:

- Research Question 2

- Does the simultaneous activation of two language systems increase the use of expressed pronominal subjects, irrespective of perseveration (the form of the previous subject)?

Based on the debate in the literature, different hypotheses are proposed. If the contextual distribution-via-codeswitching hypothesis (Torres-Cacoullos and Travis 2011, 2016; proposal) is accurate, the increase of expressed pronominal subjects will occur equally in the monolingual and bilingual conditions so long as the preceding subject (the prime) is an expressed pronominal subject. In contrast, the convergence-via-codeswitching hypothesis Toribio's (2004) proposal, following (Backus 2004; Gardner-Chloros and Edwards 2004; Gumperz and Wilson 1971; Myers-Scotton 2002; Sebba 1998; Thomason 2001), that convergence between the languages is enhanced in CS) would find support if a higher 
use of expressed pronominal subjects in bilingual (LS and CS) conditions than in monolingual conditions were attested in our data, crucially even in the CS context when the preceding subject is an omitted subject.

If bilinguals are found to exhibit more expressed pronominal subjects when one of the linguistic systems has been activated to a higher degree than in monolingual mode, as in LS or CS, a further question emerges:

- Research Question 3

- If attested, is convergence between the languages equally prevalent in LS and CS contexts?

Since, to the best of our knowledge, no single study to date has examined the effects of different bilingual modes, we cannot make any predictions; for that reason, we adhere to the null hypothesis.

\subsection{Methods: participants, materials, and procedures}

In addressing the above research questions and testing the predictions, we analyze the oral productions of 26 Spanish-English heritage bilinguals in controlled elicitations. These participants, all university students, ranged in age from 18 to 21 and were born in the U.S., i.e., they are second-generation heritage speakers. All were English dominant and demonstrated advanced abilities in Spanish, as indicated in self-reports, where they evaluated their spoken Spanish above 5 on a 7 point scale $(1=$ minimal abilities, $4=$ moderate abilities and 7 =native-like abilities), and corroborated with a segment of the DELE (Diploma del Español como Lengua Extranjera), with scores between 40 and $50(\text { maximum }=50)^{2}$

In order to elicit the language samples that would allow us to test our predictions, we created materials for three experimental sessions in which language samples were collected in structured oral elicitations. Each session began with participants reading a short story silently, followed by an oral short-answer comprehension task. What distinguished the sessions was the language(s) of the instructions, stimuli and elicited productions. The first session was a Spanish-only or monolingual condition, in which the fairy tale

2 It is important to point out that the participants spoke different varieties of Spanish. Dialectal variation with respect to expressed pronominal subject rates has been widely attested in the literature (Otheguy and Zentella 2012). In this case, the comparisons drawn are within participants, from contexts where they are speaking only Spanish to contexts where they are in LS or CS modes. Thus, dialectal variation is constant across conditions. 
and comprehension questions were presented in Spanish and participants were asked to reply orally using Spanish exclusively. The second session was a Language Switching (LS) condition, in which the stimuli were presented in English and participants were asked to react to the stimuli employing Spanish. Finally, the third session was a CS condition, in which both languages were used in the stimuli and participants were free to use whichever language(s) they desired in their responses. ${ }^{3}$ In the CS mode, participants were exposed to stimuli that mirrored some of the types of grammatical CS observed among Spanish-English bilinguals in the U.S. Crucially, participants were free to reply using whichever languages(s) they preferred (including a combination of the two), which rendered spontaneous, albeit controlled, oral speech samples of Spanish-English CS. The data was collected in a familiar space for the participants: a computer classroom where the students meet regularly. As pointed out by Nagy (2014), this space may affect participants' responses. In this case it is the classroom where they hold their Spanish for bilinguals class. Thus, it is a space where they are encouraged to use their Spanish. Although we collected the data from each participant in a single day, we provided breaks between the three stories and related activities from the larger study, so that there was a time lag between the different sessions. Each of the three sessions focused on a short story adapted from Zeballos (1997) El venado herido (for the monolingual Spanish condition), The lightening bolt (LS condition) and El gallo named Cocko-doodle-do (CS condition) respectively, edited for comparable length (190-207 words) and target structures. An overview of these conditions is provided in Table 1.

Table 1: Materials.

\begin{tabular}{lll}
\hline $\begin{array}{l}\text { Session/Language } \\
\text { Mode Condition }\end{array}$ & Language of the story & $\begin{array}{l}\text { Language of instructions, questions, and } \\
\text { prompts for responses }\end{array}$ \\
\hline Monolingual Spanish & Spanish & Spanish \\
LS & English & Spanish \\
CS & CS & CS \\
\hline
\end{tabular}

All of the instructions, directions, narratives, and short-answer prompts were presented using the written modality on a computer screen, and participant

3 The sessions were always presented in a fixed order, with the monolingual mode first, to avoid asking participants to switch from a bilingual mode to a monolingual mode. However, see González-Vilbazo et al. (2013) for a discussion on possible issues derived from using a fixed order. 
responses were digitally recorded via head-mounted microphone. We concede that the research methodology might bring about a loss in the naturalness that is the goal of sociolinguistic studies, in particular, corpus-based spontaneous speech studies, but we maintain that, as compared to psycholinguistic studies, it brings more naturalness to the tasks, while still benefitting from controlling for the relevant linguistic factors. One methodological aim, then, was to find a balance between naturalistic and controlled studies using a monitored elicited production task. Participants briefed after they completed all tasks reported believing they were working on a reading comprehension activity. Thus, although not a naturalistic method of data collection it exhibited decreased metalinguistic awareness as compared to psycholinguistic tasks.

The short-answer elicitations targeted perseveration of subjects by manipulating the prompt, or the form of the previous subject, as in the sample items in (7)-(9). In the Spanish-only condition (7), there were three possible subject forms in the prompt: lexical (el Abuelo Lino), pronoun (él), or an omitted subject. In the language switching condition (8), there were two possible subject forms- an English lexical (Grandpa Lino) or pronominal (he) subject - since the prompts were in English. Finally, there were five possible subject forms in the CS condition (9): English lexical subjects (Grandpa Lino), English pronoun (he), Spanish lexical subjects (el Abuelo Lino), Spanish pronoun (él), or Spanish unexpressed subject.

(7) Spanish-only condition

a. ¿Dónde vivía el Abuelo Lino?

'Where did Grandpa Lino live?'

Response: El abuelo vivía en un bosque (Participant \#12)

'The gradfather lived in a forest.'

b. ¿De qué se alimentaba él?

'What did he eat?'

Response: El abuelo se alimentaba de lo que la naturaleza le ofreció: nueces, frutas, y vegetales de su jardín. (Participant \#21)

'The grandfather fed on what nature had to offer: walnuts, fruit, and vegetables from his garden.'

c. ¿Dónde encontraba $\emptyset$ su comida?

'Where did he find his food?'

Response: Él encontraba su comida en el bosque y que había en el monte que rodeaba su cabina. (Participant \#23)

'He found his food in the forest and what he found in the mountain surrounding his cabin.' 
(8) LS condition

a. What was Grandpa Lino doing out in the woods?

Response: El abuelo Lino estaba estaba todo el día en el bosque cazando animales. (Participant \#24)

'Grandpa Lino spent the entire day in the forest hunting animals.'

b. Why couldn't he light the lamp?

Response: El abuelo Lino no tenía fósforos para la... no tenía no tenía fósforos. (Participant \#36)

'Grandpa Lino didn't have matches for the... he didn't have matches.'

(9) CS condition

a. ¿What did Grandpa Lino have en su cabina en el bosque?

'What did Grandpa Lino have in his cabin in the forest?'

Response: Grandpa Lino had un trueno y luz en su cabina del bosque. (Participant \#34)

'Grandpa Lino had a lightening and light in his cabin in the forest.'

b. ¿What did he see bajo el árbol?

'What did he see under the tree?'

Response: Bajo el árbol all he saw was a plump wolf. (Participant \#23)

'Under the tree all he saw was a plump wolf.'

c. ¿Qué animal tenía el abuelo Lino as a friend?

'What animal did Grandpa Lino have as a friend?'

Response: El animal que tuvo el abuelo Lino como su friend was a chicken, a rooster. (Participant \#38)

'The animal that Grandpa Lino had as his friend was a chicken, a rooster.'

d. ¿Qué encontró él in the cabin and surrounding areas?

'What did he find in the cabin and surrounding areas?'

Response: Abuelo Lino pensaba que el gallo was missing en los surrounding areas pero solamente encontró sus scattered feathers. (Participant \#41)

'Grandpa Lino thought that the rooster was missing in the surrounding areas but he only found his scattered feathers.'

e. ¿Qué escuchó $\emptyset$ loud in the distance?

'What did he hear loud in the distance?'

Response: He heard the singing of the rooster, the quiquiriqui that he usually heard in the mornings. (Participant \#48)

'He heard the singing of the rooster, the cockadoodledo that he usually heard in the mornings.' 
Each condition included at least three tokens of each subject form. Specifically, the Spanish-only condition had 9 questions (3 tokens x 3 subject forms), the English-only condition had 8 questions (4 tokens x 2 subject forms), and the CS conditions had 15 questions (3 tokens $x 5$ subject types), which required separate statistical analysis. ${ }^{4}$ The sentences were controlled for variables that have been found in the variationist literature to have an effect on subject expression: (i) discourse function (all the contexts consisted of topic continuation); (ii) person/number and animacy of the referent (all sentences referred to Grandpa Lino; a third person singular animate referent); (iii) TAM (all sentences were in the past tense); and (iv) clause type (all tokens were in a main clause). ${ }^{5}$ The productions were transcribed, and coded for subject form produced per prime type and condition, as depicted in Table 2.

Table 2: Variables.

\begin{tabular}{lll}
\hline Variable & Level & Coding \\
\hline Response (DV) & Spanish lexical & {$[$ SubjectForm $=1.0]$} \\
& Spanish pronoun & {$[$ SubjectForm $=2.0]$} \\
& Spanish omitted & {$[$ SubjectForm $=3.0]$} \\
& English lexical & {$[$ SubjectForm $=4.0]$} \\
& English pronoun & {$[$ SubjectForm $=5.0]$} \\
Prime type (IV) & Spanish lexical & {$[$ Primetype $=1.0]$} \\
& Spanish pronoun & {$[$ Primetype $=2.0]$} \\
& Spanish omitted & {$[$ Primetype $=3.0]$} \\
& English lexical & {$[$ Primetype $=4.0]$} \\
& English pronoun & {$[$ Primetype $=5.0]$} \\
Session/Language mode (IV) & Spanish-only & {$[$ Session $=1.0]$} \\
& Language switching $($ LS) & {$[$ Session $=2.0]$} \\
& Code-switching $($ CS $)$ & {$[$ Session $=3.0]$} \\
\hline
\end{tabular}

4 The different number of tokens was necessary given the differences across languages (Spanish has omitted or omitted pronominal subjects and English does not) as well as the different number of options (more options in CS when the subject can have all three forms from Spanish plus the two forms from English). As a result, the statistical analysis had to be run separately for each session (see results section). We acknowledge that having had the same number of tokens per session would have facilitated the direct comparison across conditions. 5 In the interest of maintaining naturalness, the length of the prompt could not be strictly restricted as it tends to be in the psycholinguistic literature. All Spanish-only prompts were between four and ten words long (including function words), all LS prompts were between six and ten words long, and all CS prompts were between six and eleven words long. 
With this design, 32 tokens were elicited from each participant, although some tokens were lost due to the nature of the task (e.g., participant skipped the question or did not respond with a conjugated verb form), resulting in a total of 513 tokens, controlled for numerous variables reported in the previous literature to have an effect on subject expression. The data were submitted to statistical analysis using SPSS v.21. In order to answer the first research question, on the presence of perseveration, three multinomial regressions were performed (one for each session/language mode: Spanish-only, LS, and CS) to compare responses depending on each of the prime types. Separate analyses for each session were necessary since not all prime types could be used in all sessions. For instance, in the Spanish-only session, English lexical subjects or English pronouns could not be used as primes. Similarly, so as to respond the second and third research questions, on the difference between the monolingual and the bilingual modes, comparisons between responses in Spanish-only vs. LS vs. CS conditions were run for each prime type, with a total of five multinomial regressions performed. These separate analyses were also necessary because some prime types could only be used in some of the sessions. The results are presented and discussed in the next sections.

\subsection{Results}

The effects of perseveration on subject expression were examined through the manipulation of the subject form in the text comprehension elicited production task across the three sessions of the study: monolingual Spanish, SpanishEnglish LS, and Spanish-English CS. The data were submitted to a multinomial logistic regression with the subject form produced as the dependent variable and prime type and session (or speaker language mode) as independent variables. The results revealed a relationship between the dependent variable and the combination of independent variables, $X^{2}(12, \quad \mathrm{~N}=513)=182.91, \quad \mathrm{p}<0.01$. Additionally, each of the independent variables also had an individual effect on the dependent variable (Session, $X^{2}(4, N=513)=31.68, p<0.01$; Prime type, $\left.\mathrm{X}^{2}(8, \mathrm{~N}=513)=143.88, \mathrm{p}<0.01.\right)$.

The variable Session (Spanish-only, LS, and CS) had an effect on speakers' production of subject forms. Speakers' odds ratio of producing a lexical over a pronominal subject in the Spanish monolingual session vs. the CS session decreased by $40 \%$. The lexical subject's odds ratio, on the contrary, increased in LS as compared to the CS session. Therefore, our results indicate that the condition where lexical subjects were favored over pronouns was in LS, followed by CS, and the monolingual Spanish condition. Regarding the odds ratio of omitted subjects vs. pronouns, omitted subjects were more likely to be 
produced in the Spanish monolingual session than in the CS session; but, they were equally as likely in the LS condition as in the CS condition. These results, however, have to be interpreted with caution as not all conditions allowed for the same type of primes (e.g., the Spanish monolingual session used only Spanish primes, the LS session only English primes and CS used both).

Given these differences, contrasts were made separately to understand priming effects, in each of the sessions, and session effects in each of the prime types. To facilitate the understanding of the upcoming presentation of results, the following table summarizes the comparisons that were made and highlights in bold the contrasts that were returned as significant.

As shown in Table 3, to better understand the data, we performed a series of multinomial logistic regressions for each of the sessions in order to examine the effect that each of the primes had in each session. Different sessions had different prime stimuli and different possible responses. As will become apparent in the next section, across sessions the prime type that significantly affected participants' productions were lexical subjects, in both languages. Likewise, separate analyses were performed to examine the effect of the session on each type of prime. As shown in Section 3.3.2, only those primes with an omitted subject in the prime returned a significant effect for speaker mode (i.e., session). For each analysis, we present descriptive statistics (multinomial probabilities) and the regression model statistics, which include information on whether the variable was returned as significant or not. Lastly, if the variable was found to be significant, further information is provided contrasting the different levels of the variable (parameter estimations).

Table 3: Contrasts.

\begin{tabular}{|c|c|c|c|}
\hline \multicolumn{2}{|c|}{ Priming effects across sessions } & \multicolumn{2}{|c|}{ Session effects across prime types } \\
\hline Spanish only & $\begin{array}{l}\text { Spanish lexical prime } \\
\text { Spanish pronoun prime } \\
\text { Spanish omitted prime }\end{array}$ & $\begin{array}{l}\text { Spanish lexical prime } \\
\text { Spanish pronoun prime }\end{array}$ & $\begin{array}{l}\text { Spanish only } \\
\text { Codeswitching } \\
\text { Spanish only }\end{array}$ \\
\hline Language switching & $\begin{array}{l}\text { English lexical prime } \\
\text { English pronoun prime }\end{array}$ & Spanish omitted prime & $\begin{array}{l}\text { Codeswitching } \\
\text { Spanish only }\end{array}$ \\
\hline Codeswitching & $\begin{array}{l}\text { Spanish lexical prime } \\
\text { Spanish pronoun prime } \\
\text { Spanish omitted prime } \\
\text { English lexical prime } \\
\text { English pronoun prime }\end{array}$ & $\begin{array}{l}\text { English lexical prime } \\
\text { English pronoun prime }\end{array}$ & $\begin{array}{l}\text { Codeswitching } \\
\text { Language switching } \\
\text { Codeswitching } \\
\text { Language switching } \\
\text { Codeswitching }\end{array}$ \\
\hline
\end{tabular}




\subsubsection{Perseveration effects: within modes comparison}

In order to assess whether the variable prime type had an effect on participants' use of a lexical, pronominal, or omitted subject in their responses, three analyses were performed (one for each session/language mode). To facilitate comparisons, Table 4 presents the percentages and number of tokens for each of the three Spanish responses: lexical, pronominal and omitted or unexpressed subjects). To facilitate the upcoming presentation of results, we have highlighted the primes that were returned as having a significant effect. In the CS condition, participants could also respond with an English lexical or a pronominal subject. The percentages of Spanish and English responses, however, have been calculated separately here to present comparable results across conditions.

Table 4: Results: Descriptive statistics.

\begin{tabular}{|c|c|c|c|c|}
\hline Session & $\begin{array}{l}\text { Response } \\
\text { Primetype }\end{array}$ & $\begin{array}{r}\text { Spanish } \\
\text { lexical } \\
\%(N)\end{array}$ & $\begin{array}{r}\text { Spanish } \\
\text { pronoun } \\
\%(\mathrm{~N})\end{array}$ & $\begin{array}{r}\text { Spanish } \\
\text { omitted } \\
\%(\mathrm{~N})\end{array}$ \\
\hline \multirow[t]{3}{*}{ Spanish only } & Spanish lexical prime & $65.3 \%(47)$ & $8.3 \%(6)$ & $26.4 \%(19)$ \\
\hline & $\begin{array}{l}\text { Spanish pronoun } \\
\text { prime }\end{array}$ & $9.5 \%(7)$ & $43.2 \%(32)$ & $47.3 \%(35)$ \\
\hline & $\begin{array}{l}\text { Spanish omitted } \\
\text { prime }\end{array}$ & $12.7 \%(9)$ & $32.4 \%(23)$ & $54.9 \%(39)$ \\
\hline Language & English lexical prime & $69 \%(69)$ & $7 \%(7)$ & $24 \%(24)$ \\
\hline switching & $\begin{array}{l}\text { English pronoun } \\
\text { prime }\end{array}$ & $29.4 \%(30)$ & $34.3 \%(35)$ & $36.3 \%(37)$ \\
\hline \multirow[t]{5}{*}{ Codeswitching } & Spanish lexical prime & $80.9 \%(55)$ & $5.9 \%(4)$ & $13.2 \%(9)$ \\
\hline & $\begin{array}{l}\text { Spanish pronoun } \\
\text { prime }\end{array}$ & $24.2 \%(15)$ & $50.0 \%(31)$ & $25.8 \%(16)$ \\
\hline & $\begin{array}{l}\text { Spanish omitted } \\
\text { prime }\end{array}$ & $29.8 \%(17)$ & $43.9 \%(25)$ & $26.3 \%(15)$ \\
\hline & English lexical prime & $60 \%(27)$ & $15.6 \%(7)$ & $24.4 \%(11)$ \\
\hline & $\begin{array}{l}\text { English pronoun } \\
\text { prime }\end{array}$ & $25.5 \%(12)$ & $36.2 \%(17)$ & $38.3 \%(18)$ \\
\hline
\end{tabular}

Recall that in the Spanish monolingual mode condition only Spanish (lexical subjects, expressed pronouns, and omitted subjects) were used as prime stimuli. Similarly, the only possible subject form in the responses was a Spanish lexical, pronominal, or an omitted subject. The Spanish monolingual language mode data revealed that, with a Spanish lexical prime, participants provided a Spanish 
lexical subject in their response $65.3 \%$ of the time, as compared to $8.3 \%$ of the time when they produced a Spanish pronoun and $26.4 \%$ of the time when an omitted was produced. With an expressed Spanish pronoun in the prime, however, both expressed pronouns and omitted subjects were produced at similar rates (43.2\% and 47.3\% respectively) and more frequently than Spanish lexical subjects $(9.5 \%$ of the time). With Spanish omitted subjects in the prime, participants produced more omitted subjects (54.9\% of the time) than pronouns (32.4\%) and Spanish lexical subjects (12.7\%).

In the monolingual mode, Spanish-only session, Prime type was returned as a significant factor, $X^{2}(4, \mathrm{~N}=165)=53.79, \mathrm{p}<0.01$. The parameter estimates for the Spanish monolingual session provides the odds ratio of using a lexical subject instead of an expressed pronoun in Spanish when presented with a Spanish lexical, a Spanish pronominal, and a Spanish omitted subject as a prime in the question. This analysis likewise compares the odds ratio of using an omitted subject instead of an expressed pronominal subject in Spanish when presented with the different types of prime forms. Only one of the comparisons was returned as significant in this session. The odds ratio of using a lexical over a pronominal subject steeply increased with lexical subjects as primes over omitted subjects as primes $(\mathrm{p}<0.01)$. It was, however, not different when the prime was an expressed pronoun than when it was an omitted subject $(p>0.05)$. With respect to omitted vs. pronoun contrasts, the odds ratio of using omitted subjects over pronouns was the same with a lexical or a pronominal prime than with an omitted prime $(\mathrm{p}>0.05)$.

The LS data, where participants were asked comprehension questions in English and had to respond in Spanish, revealed that, with an English lexical prime, participants predominantly produced a Spanish lexical subjects in their responses $(69 \%$ of the time vs. $7 \%$ production of a Spanish pronoun and $24 \%$ production of omitted subjects). With an English pronoun in the prime, however, the distribution of responses is more widespread (36.3\% omitted subjects, 34.3\% Spanish pronouns, and 29.4\% Spanish lexical subjects). In the LS condition, the type of prime (English lexical or English pronominal subjects) had an effect on the participants' production of subject expression in Spanish, $X^{2}(2, N=150)=$ 53.74, $\mathrm{p}<0.01$. The parameter estimates for the language switching session compared the use of Spanish lexical subjects vs. pronouns as well as the use of omitted vs. expressed pronouns in response to English lexical and pronominal subjects in the primes. The odds ratio of producing a lexical over a pronominal subject increases following an English lexical prime, as compared to an English pronoun $(\mathrm{p}<0.01)$. With an English lexical subject, too, the odds ratio of using an omitted vs. a pronoun increase as compared to conditions with an English pronoun in the prime $(\mathrm{p}<0.05)$. 
In the CS condition, the use of a Spanish lexical vs. a Spanish pronominal vs. a Spanish omitted subject depending on the prime used indicate that, with a Spanish lexical prime, participants largely produced a Spanish lexical subject (80.9\%, vs. 5.9\% pronouns and 13.2\% omitted subjects). With a Spanish pronoun, participants produced more Spanish pronouns (50\%) than omitted subjects (25.8\%) and Spanish lexical subjects (24.4\%). With a Spanish null, participants produced more Spanish pronouns (43.9\%) than Spanish lexical subjects (29.8\%) and pronouns (26.3\%). With an English lexical subject, participants produced more Spanish lexical subjects (60\%) than omitted subjects (24.4\%) and Spanish pronouns (15.6\%). Lastly, with an English pronoun, participants produced Spanish omitted subjects (38.3\%) at similar rates as Spanish pronouns (36.2\%) and slightly more than Spanish lexical subjects (25.5\%).

The regression model indicated that the type of prime was a relevant factor at predicting the odds ratio of producing a lexical vs. a pronominal or an omitted pronominal subject in the CS language mode, $X^{2}(8, N=198)=58.10, p<0.01$. The parameter estimates for the CS language mode compared the use of lexical to pronominal subjects as well as omitted to pronominal subjects across the five possible prime types (Spanish lexical, pronominal, omitted subjects and English lexical and pronominal subjects). The results summarized showed the increased effect that English and Spanish lexical subjects had on the odds ratio of producing a lexical vs. a pronominal subject $(p<0.01)$. In contrast, there was no effect for the omitted vs. pronominal prime $(p>0.05)$. That is, the distribution of omitted vs. expressed pronominal subjects was not affected by the form of the prime in CS.

In this section, the results for the effects of the different primes were reported within monolingual and bilingual modes, induced in three sessions (Spanish only, LS, and CS). The perseveration effects of lexical subjects (in either language) over lexical subjects were attested across sessions. Pronominal perseveration was only observed in the LS condition, where the prime is in English. Even though it did not reach significance for the CS condition, the element that primed the most prolific production of Spanish pronouns was the English pronoun. In the following section, we report the results that address our second research question regarding the effects of bilingual modes by examining the effects of the different primes across the different sessions.

\subsubsection{Bilingual mode effects: across modes comparisons}

We compared the results for the effect that bilingual speaker modes had on the production of a specific subject form in response to a controlled prime or 
Table 5: Results: Descriptive statistics for comparisons across modes.

\begin{tabular}{llrrr}
\hline Primetype & Response & $\begin{array}{r}\text { Spanish } \\
\text { lexical }\end{array}$ & $\begin{array}{r}\text { Spanish } \\
\text { pronoun }\end{array}$ & $\begin{array}{r}\text { Spanish } \\
\text { omitted subject }\end{array}$ \\
\hline Spanish lexical prime & Spanish only & $65.3 \%$ & $8.3 \%$ & $26.4 \%$ \\
& Codeswitching & $80.9 \%$ & $5.9 \%$ & $13.2 \%$ \\
Spanish pronoun prime & Spanish only & $9.5 \%$ & $43.2 \%$ & $47.3 \%$ \\
& Codeswitching & $24.2 \%$ & $50.0 \%$ & $25.8 \%$ \\
Spanish omitted prime & Spanish only & $12.7 \%$ & $32.4 \%$ & $54.9 \%$ \\
& Codeswitching & $29.8 \%$ & $43.9 \%$ & $26.3 \%$ \\
English lexical prime & Language switching & $69.0 \%$ & $7.0 \%$ & $24.0 \%$ \\
& Codeswitching & $60.0 \%$ & $15.6 \%$ & $24.4 \%$ \\
English pronoun prime & Language switching & $29.4 \%$ & $34.3 \%$ & $36.3 \%$ \\
& Codeswitching & $25.5 \%$ & $36.2 \%$ & $38.3 \%$ \\
\hline
\end{tabular}

previous subject form. Recall that certain primes could only appear in certain bilingual speaker modes, e.g., the Spanish primes can only be compared in the Spanish-only and CS conditions, and the English primes can only be compared in the LS and CS conditions. Table 5 provides a comparison of the percentages of use of each response presented above between modes. To facilitate the upcoming presentation of results, we have highlighted the primes that were returned as having a significant effect.

The conditions where Spanish lexical subjects are used as primes (all except the LS condition) yield a useful model where session is a significant factor, $X^{2}$ (2, $\mathrm{N}=102)=7.26, \mathrm{p}<0.05$. The parameter estimates, however, revealed that there were no statistical differences between the monolingual and the CS sessions ( $p>0.05)$. Therefore, the higher use of lexical subjects than pronominal subjects with a lexical prime was similar in the monolingual and the CS language modes. Likewise, the low use of omitted and pronominal subjects with a lexical prime was similar in the monolingual and CS conditions ( $p>0.05)$. In the case of Spanish expressed pronouns, the model returned session as significant, $X^{2}(2, \mathrm{~N}=98)=$ $6.26, \mathrm{p}<0.05$. Therefore, taking the session into account improved the model. The results from the parameter estimates indicated that no differences between the Spanish-only and the CS condition were attested ( $>>0.05)$. The model for Spanish omitted primes is also improved by including the variable session since it was returned as significant, $X^{2}(2, \mathrm{~N}=97)=14.2, \mathrm{p}<0.01$. Spanish omitted subjects - in contrast with Spanish lexical and pronominal subjects - showed a higher perseveration effect in Spanish than in the CS condition $(p<0.01)$, that is, participants used significantly more Spanish omitted subjects in response to omitted primes in the Spanish-only condition than in the CS condition. 
A comparison of perseveration effect of English lexical and pronominal primes between the LS and CS conditions was performed. With English lexical primes, the variable Session was not returned as significant, $X^{2}(2, N=108)=$ 5.94, $\mathrm{p}>0.05$. Therefore, we can conclude that with English lexical primes there are no differences between LS and CS. Regarding the English pronoun prime, the model's accuracy is below the proportional-by-chance accuracy. Therefore, we cannot make any generalizations from these data regarding the differences in subject expression between the LS and the CS conditions.

To briefly summarize this section, the crucial condition for our second research question, session contrasts with an omitted prime, indicated a higher use of expressed pronominal subjects in the CS condition than in the Spanishonly condition even when the prime was an omitted pronominal subject. With these results in mind, we return to our research questions in the following section.

\section{Discussion}

The speech data obtained from the short-answer elicitation task performed by 26 advanced heritage Spanish-English bilingual speakers were submitted to statistical analysis to examine the effects of perseveration and speaker modes on the realization of expressed versus unexpressed subjects, a noted variable phenomenon of Spanish. The general model revealed that there were effects of both perseveration and speaker mode in these bilinguals' productions.

The perseveration effects were most consistent with lexical subjects in the prime in all three sessions: monolingual mode, language switching (LS) and code-switching (CS). In the LS session, unlike in the other two sessions, perseveration was also attested with English pronouns, which primed the use of Spanish pronouns. With these results, we return to our first research question: Is there evidence of intra- and cross-linguistic perseveration in the participants' productions in Spanish monolingual mode, LS, and CS? The data indicated that there was structural perseveration although not uniformly: There was perseveration of lexical subjects in monolingual Spanish, LS, and CS; there was perseveration of pronouns only in LS; and there was no structural perseveration with omitted subjects in any condition. We anticipated participants' productions would show evidence of intra-linguistic and cross-language perseveration in the different modes but perhaps not uniformily across subject forms. Otheguy (2015) argues that omitted subjects are not categories and, as a result, cannot prime other omitted forms, which is precisely what their data show. Thus, the 
lack of perseveration with omitted subjects is a result consistent with Otheguy (2015). Lexical subjects, on the contrary, are rather infrequent in the context of the task. Schwenter and colleagues have argued that forms that are less frequent show a stronger perseveration effect (Rosemeyer and Schwenter 2017; Schwenter and Cacoullos 2008; inter alia). Thus, it is possible that the oddity of the use of lexical subjects in the context of a story with only one human referent may have made lexical subjects, in addition to being infrequent, more salient, and, thus, a better target for perseveration. The perseveration of pronouns was anticipated, although not only in LS. The data from the other two sessions, however, showed mixed results, as evidence of perseveration was only attested with lexical subjects, but not with pronominal or omitted subjects. This is so in spite of the unnaturalness of the use of lexical subjects in the response to questions with a lexical prime in the question. This result may be explained, in addition to its saliency for priming (Rosemeyer and Schwenter 2017; Schwenter and Cacoullos 2008), as a task effect, where participants were asked to respond with a complete sentence. While the reminder to respond with a complete sentence appeared with each question, it is possible that the presence of a lexical subject in the question may have served as a more salient prompt. Thus, this result may not be consistent with data from spontaneous production. In general, it is possible that the experimental design with question-answer sequences may have weaken the perseveration reported in this study. Gries (2005) found that "comprehension-to-production" perseveration (across speakers) is weaker than "production-to-production" (same-speaker) perseveration. Additionally, the questions exhibited post-verbal subjects while the answers had pre-verbal subjects, which could have had an effect. Given that cross-language perseveration is already weaker than within-language perseveration (e.g., Bernolet et al. 2013; Schoonbaert et al. 2007), the further weakening imposed by the experimental set up may be creating an artificially diminished perseveration effect, in particular in the cross-language condition.

It has been previously shown that differences are attested depending on the type of bilingual, which in our case is a 'trained' undergraduate student (Benmamoun et al. 2010) as well as the type of task (Nagy 2014). Thus, the results presented in this paper are limited to a specific group and may not be representative of heritage speakers as a whole. Additionally, the task, while being more naturalistic than other tasks used in the study of CS as well as perseveration, is an experimental task performed in an institutional context. Thus, these results need to be contrasted with those from other types of heritage speakers and tasks in order to have a more complete understanding.

The lack of significant differences in the use of omitted and expressed pronominal subjects across sessions also merits further discussion. Although 
the present study did not aim to examine contact effects on the expression of personal subjects in Spanish, some of the results are consistent with the results of previous studies that report a language contact effect on subject expression. (e.g., Otheguy and Zentella 2012). In this study, we examine third person singular data. Thus, the lack of significant differences between omitted and expressed pronominal subjects in our data is consistent with the literature on third person subject expression in Spanish in contact with English, which reports a contact effect. Further comparison with a monolingual Spanish speaker group would be necessary, however, to confirm a language contact effect. Since our data were obtained from an experimental elicited production task and is not directly compared to data from a monolingual Spanish speaker group, this contact effect could not be confirmed, although a similar rate of omitted and expressed pronominal subjects was attested in our data.

The previous literature on SPE in Spanish-English CS consistently found an increase in expressed pronoun use in bilinguals' CS vs. non-CS speech (Toribio 2004; Torres-Cacoullos and Travis 2011, 2016). In order to further examine what this effect might be attributed to (activation of two systems vs. the specific perseveration from a previous subject type), we isolated the effect of perseveration by controlling for subject form in the question and examining the subject form in participant responses for each prime type. Therefore, with these data we can address our research question on bilingual modes: Does the simultaneous activation of two language systems increase cross-linguistic perseveration? We hypothesized that in cases where both linguistic systems were simultaneously active (even to different degrees), as in LS and CS, bilinguals would exhibit greater cross-linguistic perseveration than in contexts where one of the bilinguals' composite languages is more inhibited, as in monolingual mode (Green 1986). The data returned a significant effect for session. This effect, however, did not reach significance across prime types. With Spanish lexical primes and pronouns and English lexical subjects, for instance the contrast among modes did not reach significance, which means that the perseveration was the same in the monolingual as in the bilingual mode conditions. Additionally, there were inconclusive results with English pronoun primes. Nonetheless, an effect of bilingual mode, independent of perseveration, was attested with Spanish unexpressed subject as primes. When participants were primed with an omitted subject, there was an increase in the use of expressed pronominal subjects in bilingual conditions (the CS condition in particular) as compared to monolingual Spanish conditions. This is consistent with Toribio's (2004) claim that the use of expressed pronouns instead of omitted subjects in Spanish is expected in CS independently of perseveration (in contrast with Torres-Cacoullos and Travis 2011, 2016). Thus, we can conclude that the simultaneous activation of two 
language systems did not increase intra-linguistic perseveration with lexical and pronominal subjects in 3sg subjects. The effect that was found - an increase in pronoun use in LS and CS as compared to monolingual Spanish with an omitted subject prime - cannot be attributed to perseveration but to the mode itself. The contrast with Torres-Cacoullos and Travis $(2011,2016)$ could be attributed to the verb person, since 1sg and 3sg differ in important ways. For instance, the nature of $1 \mathrm{sg}$ subjects is deictic while $3 \mathrm{sg}$ subjects are referential. Crucially, crosslinguistic effects in subject expression seem to be selective when it comes to person (Geeslin and Gudmestad 2016; Gudmestad et al. 2013; Prada Pérez and Gómez Soler, forthcoming). Thus, it is not surprising that convergence via codeswitching would only apply to 3sg subjects. Differences in the materials and study design, however, call for further research; in particular, examining 3sg subjects in oral corpora can offer further insight on these seemingly contradictory results. Importantly, it is possible that both the convergence-via-codeswitching hypothesis and the contextual distribution-via-codeswitching hypothesis are both compatible. There is ample evidence here and elsewhere that perseveration (contextual distribution) affects the production of an upcoming form. This effect is mechanical and is expected to apply across persons and conditions, although the effects are stronger in less frequent forms. Convergence, on the other hand, has been proven to be selective in general (e.g., the grand challenge of language contact selectivity) and, in particular, in terms of subject persons in Spanish. Thus, rather than arbitrate between these two proposals, this paper argues that both processes are at work here, which implies that there is a convergence-viacodeswitching effect, independent of perseveration, in 3sg subject expression in Spanish-English codeswitching.

The follow-up research question sought to compare within the bilingual mode (LS vs. CS). Contrary to the prediction that there would not be a significant difference (the null hypothesis), we found that LS had a stronger effect than CS in the production of lexical over pronominal subjects. The difference is not statistically significant with respect to the production of expressed vs. unexpressed pronominal subjects. Expressed lexical subjects are phonologically more prominent and tend to be used to introduce a new referent, in line with the Accessibility Theory (see Ariel 2001, for an overview). The hypothesis we offer at this time, pending further testing, is that the relationship between the response subject and the prime may be more disconnected in the LS condition, which may favor the production of full lexical items over potentially ambiguous expressed pronouns or omitted subjects. As explained in the variationist literature, connectedness in the discourse, as in the combination of switch reference and TAM continuity, exerts a strong effect on subject expression (cf. the Speech connectedness variable in Otheguy et al. 2007). The more connected the speech (same 
referent and same TAM), the more likely it is for a speaker to use an omitted form. If LS is perceived as less connected, it might explain the higher use of lexical subjects in LS than in the other two modes.

In sum, the analysis indicates that perseveration effects as well as bilingual mode effects were attested in our data. Further testing revealed that in Spanish monolingual mode, lexical subjects primed lexical subjects, whereas the effect of perseveration on pronouns and omitted subjects was not as strong. In LS, English lexical and pronominal subjects primed Spanish lexical and pronominal subjects respectively. In CS, perseveration effects were only attested with lexical subjects, just as in monolingual mode. Therefore, we can conclude that perseveration was present in our data, but not pervasively. Interestingly, perseveration was more evident with lexical subjects and in the LS condition. Regarding bilingual mode effects, there were significant differences in the use of expressed pronominal subjects with Spanish omitted pronominal subjects as primes in the CS session as compared to the Spanish monolingual session. This result indicates that even when perseveration is controlled for, there is some effect of bilingual mode on subject expression (convergence-via-codeswitching). Additionally, this effect occurs equally in LS as in CS.

\section{Conclusions}

Variable language phenomena have been empirically shown to demonstrate effects of syntactic perseveration. This study has focused on one of the most researched variable phenomena in Spanish: subject expression. In our analysis we compared the distribution of expressed vs. unexpressed (pronominal and lexical) subjects in the elicited production of Spanish heritage speakers in the U. S. in three modes: Spanish-only (monolingual mode), English-to-Spanish language switching mode, and Spanish-English code-switching mode. On the one hand, we examined the effects of perseveration across modes using both English and Spanish primes. We reported statistically significant perseveration effects from Spanish and English lexical subjects across sessions and from English pronouns in the LS session. Even though we obtained significant results, the effects of structural perseveration were not as pervasive as would have been anticipated based on the previous literature (e.g., Travis 2005, 2007). The differential findings may be due to differences in methodology. Our materials are rather innovative in that, although they are experimental, they are less metalinguistic than the controlled experimental design usually employed in psycholinguistics and, similarly to sociolinguistic research, they elicit oral production, 
however, with more control over the forms and contexts produced. Thus, some of the discrepancies may have been caused by the nature of the tasks, the context of the research project, and the speakers used in our study. Examination of the speech of a single bilingual cohort with various methodologies would be useful in disentangling these issues.

On the other hand, we examined the effect that language mode has on subject expression. This line of research is innovative in inquiry on CS, where the theoretical literature has traditionally focused on identifying constraints on CS sites (e.g., Belazi et al. 1994; DiSciullo et al. 1986; MacSwan 2000; Poplack 1980; Woolford 1983), while the growing body of empirical research in bilingual pronunciation has emphasized the effect of CS on specific phonetic forms (Bullock and Toribio 2009; Olson 2012, 2013, 2015; references therein). Even though this study examined morphosyntactic phenomena in Spanish-English bilingual speech, the intent was not to identify why CS might be more or less opportune at a particular grammatical juncture (also an interesting question), but to examine the effect of CS (and LS) on subject expression. One of the proposals for the effects of CS on subject expression identifies intra- and crosslanguage perseveration (contextual distribution-via-codeswitching hypothesis, Torres-Cacoullos and Travis 2011, 2016) while another identifies convergence in CS speech as the source (convergence-via-codeswitching hypothesis, Toribio 2004). Therefore, we tested the effect of bilingual modes on the subject production of bilingual speakers while controlling for the subject form in the prime. If the effects of CS are due to perseveration from English and Spanish expressed forms, there should not be an increase in pronoun use when the speaker is primed with omitted subjects, a result that is not consistent with our data. Our participants produced expressed subjects with omitted primes in the CS condition, which can be interpreted as an indication that, in CS, convergence between the languages is enhanced (i.e., the convergence-via-codeswitching hypothesis: Backus 2004; Gardner-Chloros and Edwards 2004; Gumperz and Wilson 1971; Myers-Scotton 2002; Sebba 1998; Thomason 2001; Toribio 2004).

This interpretation is consistent with Bullock and Toribio's (2004) understanding of convergence as an enhancement of structural similarities between two systems. However, Toribio (2004) further suggests that the increased rates of pronoun expression may be a response to processing, i.e., "a reflex of a speaker's attempt at reducing the complexity (and cognitive cost) of processing two simultaneously active language systems" (2004: 172). The results can be interpreted as being consistent with the increased demand of cognitive resources involved in the simultaneous activation of both languages together with the freeing of attentional resources when using expressed subjects. The convergence with English in the present study, then, could be illusory, a fortuitous result of a 
situation where the less costly option of the expressed pronoun expression coincides with the grammar of the co-active language, English. Further research examining other language pairings is necessary to answer this question.

In general, these results call for more research with diverse variable phenomena. Subject expression is variable in Spanish, but it is largely constrained by pragmatics, as instantiated in the variable discourse function. Other morphosyntactic phenomena seem to be more variable in that no change in the semantics or pragmatics takes place between the variants (e.g., dative alternation, Hartsuiker and Herman 1998: 171). Statistical comparisons of different variable phenomena can shed light on the role that variability plays in bilingual speech. This line of research lends itself to refinement of theories of cross-linguistic language influence. In fact, Prada Pérez (2015) hypothesizes that the more variable a phenomenon is (i.e., a variant is used close to $50 \%$ of the time in a specific context), the more cross-linguistic effects will be attested. An extension of that work to CS data would predict that more variable phenomena would be subject to a greater effect of CS than less variable phenomena.

All in all, this paper offers some evidence that, at least in 3sg subjects, Spanish-English CS has a convergence effect, independent of perseveration and in addition to a perseveration effect. Thus, support is found for both the contextual distribution-via-codeswitching hypothesis, as there is evidence of intra- and cross-linguistic perseveration, and for the convergence-via-codeswitching hypothesis, as in the presence of an unexpressed preceding subjects, participants still produced more expressed subjects in CS than in the Spanish-only condition.

Acknowledgements: I would like to thank A. Jacqueline Toribio, Verónica González Lopez, and the three anonymous reviewers for their insightful comments on this project. All errors are my own.

\section{References}

Ariel, Mira. 2001. Accessibility theory: An overview. In Ted Sanders, Joost Schliperoord \& Wilbert Spooren (eds.), Text representation: Linguistic and psycholinguistic aspects, 29-87. Philadelphia, PA: John Benjamins (Human cognitive processing series).

Backus, Ad. 2004. Convergence as a mechanism of change. Bilingualism: Language and Cognition 7(2). 179-181.

Balukas, Colleen \& Chritian Koops. 2014. Spanish-English bilingual voice onset time in spontaneous code-switching. International Journal of Bilingualism 19(4). 423-443.

Belazi, Heidi M., Edward Rubin \& Almeida Jacqueline Toribio. 1994. Code-switching and X-bar theory: The Functional Head Constraint. Linguistic Inquiry 25(2). 221-237. 
Benmamoun, Elabbas, Silvina Montrul \& Maria Polinsky. 2010. Prolegomena to Heritage Linguistics. White paper. University of Illinois Urbana-Champaign and Harvard University. http://scholar.harvard.edu/mpolinsky/publications/white-paper-prolegomena-heritagelinguistics

Bernolet, Sarah, Robert J Hartsuiker \& Martin J Pickering. 2013. From language-specific to shared syntactic representations: The influence of second language proficiency on syntactic sharing in bilinguals. Cognition 127. 287-306.

Bock, J. Kathryn. 1986. Syntactic persistence in language production. Cognitive Pyschology 18. 355-387.

Bullock, Barbara E., A. Jacqueline Toribio, Verónica González \& Amanda Dalola. 2006. Language dominance and performance outcomes in bilingual pronunciation. In Mary G O'Brien, Christine Shea \& John Archibald (eds.), Proceedings of the 8th Generative Approaches to Second Language Acquisition Conference (GASLA 2006), 9-16. Somerville: Cascadilla Proceedings Project.

Bullock, Barbara E. \& A. Jacqueline Toribio. 2009. How to hit a moving target: On the sociophonetics of code-switching. In Ludmila Isurin, Donald Winford \& Kees De Bot (eds.), Multidisciplinary approaches to code switching, 189-206. Amsterdam: John Benjamins.

Cameron, Richard. 1994. Switch reference, verb class and perseveration in a variable syntax. Papers from the Regional Meeting of the Chicago Linguistics Society: Parasession on Variation in Linguistic Theory 30. 27-45.

Cameron, Richard. 1995. The scope and limits of switch reference as a constraint on pronominal subject expression. Hispanic Linguistics 6-7. 1-27.

Casanova Seuma, Lourdes. 1999. El sujeto en catalán coloquial. Revista española de lingüística 29(1). 105-131.

DiSciullo, Anne-Marie, Pieter Muysken \& Rajendra Singh. 1986. Government and codeswitching. Journal of Linguistics 22(1). 1-24.

Enríquez, Emilia. 1984. El pronombre personal sujeto en la lengua española hablada en Madrid. Madrid: Consejo Superior de Investigaciones Científicas.

Flores-Ferrán, Nydia. 2004. Spanish subject personal pronoun use in New York City Puerto Ricans: Can we rest the case of English contact?. Language Variation and Change 16. 49-73.

Flores-Ferrán, Nydia. 2007. A bend in the road: Subject personal pronoun expression in Spanish after 30 years of sociolinguistic research. Language and Linguistic Compass 1. 624-652.

Gardner-Chloros, Penelope \& Malcolm Edwards. 2004. Compound verbs in codeswitching: Bilinguals making do?. Journal of Bilingualism 11(1). 73-91.

Geeslin, Kimberly \& Aarnes Gudmestad. 2016. Subject expression in Spanish: Contrasts between native and non-native speakers for first and second-person singular referents. Spanish in Context 13(1). 53-79.

González-Vilbazo, Kay, Laura Bartlett, Sarah Downey, Shane Ebert, Jeanne Heil, Bradley Hoot, Bryan Koronkiewicz \& Sergio Ramos. 2013. Methodological considerations in codeswitching research. Studies in Hispanic and Lusophone Linguistics 6. 118-138.

Green, David W. 1986. Control, activation, and resource. Brain and Language 27. 210-223.

Gries, Stefan Th. 2005. Syntactic perseveration: A corpus-based approach. Journal of Psycholinguistic Research 34(4). 365-399.

Grosjean, Francois. 1998. Studying bilinguals: Methodological and conceptual issues. Bilingualism: Language and Cognition 1. 131-149. 
Grosjean, Francois. 2001. The bilingual's language modes. In Janet Nicol (ed.), One mind, two languages: Bilingual language processing, 1-22. Oxford: Blackwell.

Gudmestad, Aarnes, Leanna House \& Kimberly Geeslin. 2013. What a Bayesian analysis can do for the sociolinguistic study of subject expression in second-language Spanish. Language Learning 63(1). 371-399.

Gumperz, John J \& Robert Wilson. 1971. Convergence and creolization: A case from the IndoAryan/Dravidian border in India. In Dell Hymes (ed.), Pidginization and creolization of languages, 151-167. Cambridge: Cambridge University Press.

Hartsuiker, Robert J \& H.J. Kolk Herman. 1998. Syntactic persistence in Dutch. Language and Speech 41(2). 143-184.

Hartsuiker, Robert J., Martin J Pickering \& E. Veltkamp. 2004. Is syntax separate or shared between languages? Cross-linguistics syntactic perseveration in Spanish-English bilinguals. Psychological Science 15(6). 409-414.

Judith, Weiner, E. \& William Labov. 1983. Constraints on the agentless passive. Journal of Linguistics 19. 29-58.

Kroll Judith, F., M. B. Annette \& De Groot. 2005. Handbook of bilingualism: Psycholinguistic approaches. New York: Oxford University Press.

Lapidus, Naomi \& Ricardo Otheguy. 2005a. Contact induced change? Overt nonspecific ellos in Spanish in New York. In Lofti Sayahi \& Maurice Westmoreland (eds.), Selected proceedings of the 2nd Workshop on Spanish Sociolinguistics, 67-75. Somerville: Cascadilla Press.

Lapidus, Naomi \& Ricardo Otheguy. 2005b. Overt nonspecific ellos in Spanish in New York. Spanish in Context 2. 157-174.

MacSwan, Jeff. 1999. A minimalist approach to intrasentential code switching (Oustanding Dissertations in Linguistics series). New York: Garland.

MacSwan, Jeff. 2000. The architecture of the bilingual language faculty: Evidence from codeswitching. Bilingualism: Language and Cognition 3(1). 37-54.

Mahootian, Shahrzad. 1993. A null theory of codeswitching. Chicago: Northwestern University dissertation.

Meijer, Paul J. A \& Jean E. Fox Tree. 2003. Building syntactic structure in speaking: A bilingual exploration. Experimental Psychology 50(3). 184-195.

Morales, Amparo. 1997. La hipótesis funcional y $\underline{\text { la }}$ aparición del sujeto no nominal: El español de Puerto Rico. Hispania 80. 153-165.

Muysken, Pieter. 2000. Bilingual speech: A typology of code-mixing. Cambridge: Cambridge University Press.

Myers-Scotton, Carol. 1993. Social motivations for codeswitching. Evidence from Africa. Oxford: Clarendon.

Myers-Scotton, Carol. 2002. Contact linguistics. Bilingual encounters and grammatical outcomes. Oxford: Oxford University Press.

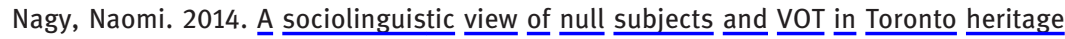
languages. Lingua 164. 309-327.

Olson, Daniel. 2012. The phonetic correlates of insertional code switching: Suprasegmental analysis and a case for hyper-articulation. Linguistic Approaches to Bilingualism 2(4). 439-457.

Olson, Daniel. 2013. Bilingual language switching and selection at the phonetic level: Asymmetric transfer in VOT production. Journal of Phonetics 41. 407-420.

Olson, Daniel. 2015. The impact of code-switching, language context, and language dominance on suprasegmental phonetics: Evidence for the role of predictability. International Journal of Bilingualism 20(4). 453-472. 
Otheguy, Ricardo. 2015. Variationist sociolinguistics and linguistic theory in the context of pronominal perseveration. In Nathalie Dion, André Lapierre \& Rena Torres-Cacoullos (eds.), Linguistic variation: Confronting fact and theory, 319-334. New York: Routledge Publishers.

Otheguy, Ricardo \& Ana C Zentella. 2012. Spanish in New York. Language contact, dialectal leveling, and structural continuity. Oxford: Oxford University Press.

Otheguy, Ricardo, Ana C Zentella \& David Livert. 2007. Language and dialect contact in Spanish in New York: Towards the formation of a speech community. Language 83. 1-33.

Piccini, Paige \& Amalia Arvaniti. 2015. Voice onset time in Spanish-English spontaneous code-switching. Journal of Phonetics 52. 121-137.

Poplack, Shana. 1980. Sometimes ! start a sentence in Spanish y termino en español: Toward a typology of code-switching. Linguistics 18. 581-618.

Prada Pérez, Ana de. 2015. First person singular subject pronoun expression in Spanish in contact with catalan. In Ana M Carvalho, Rafael Orozco \& Naomi Lapidus Shin (eds.), Subject pronoun expression in Spanish: A cross-dialectal perspective, 121-142. Washington D.C.: Georgetown University Press.

Prada Pérez, Ana de \& Andrea Hernández. 2017. Examining code-switching performance theories: Copula choice in Spanish among Cuban heritage speakers. In Alejandro Cuza (ed.), Cuban Spanish Dialectoloy: Variation, Contact and Change, 275-293. Washington D.C.: Georgetown University Press.

Prada Pérez, Ana de \& Inmaculada Gómez Soler. Forthcoming. The effect of person in the subject expression of Spanish heritage speakers. In Wilfredo Valentín-Márquez \& Melvin González-Rivera (eds.), Dialects from Tropical Islands: Research on Caribbean Spanish in the United States. New York: Routledge.

Raña Risso, Rocío. 2010. Subject pronoun placement as evidence of contact and leveling in Spanish in New York. International Journal of the Sociology of Language 203. 101-114.

Ranson, Diana L. 1991. Person marking in the wake of/s/deletion in Andalusian Spanish. Language Variation and Change 3(2). 133-152.

Rosemeyer, Malte \& Scott A Schwenter. 2017. Entrenchment and persistence in language change: The Spanish past subjunctive. Corpus Linguistics and Linguistic Theory. https://doi.org/10. 1515/cllt-2016-0047.

Scherre, Maria \& P. Marta. 2001. Phrase-level parallelism effect on noun phrase number agreement. Language Variation and Change 13. 91-107.

Schoonbaert, Sofie, Robert J. Hartsuiker \& Martin J. Pickering. 2007. The representation of lexical and syntactic information in bilinguals: Evidence from syntactic perseveration. Journal of Memory and Language 56. 153-171.

Schwenter, Scott A. \& RenaTorres Cacoullos. 2008. Defaults and indeterminacy in temporal grammaticalization: The 'perfect' road to perfection. Language Variation and Change 20. 1-39.

Sebba, Mark. 1998. A congruence approach to the syntax of codeswitching. International Journal of Bilingualism 2(1). 1-19.

Shin, Naomi Lapidus. 2013. Women as leaders of language change: A qualification from the bilingual perspective. In Ana M Carvalho \& Sara Beaudrie (eds.), Selected proceedings of the 6th Workshop on Spanish Sociolinguistics, 135-147. Somerville: Cascadilla Proceedings Project.

Shin, Naomi Lapidus \& Ricardo Otheguy. 2013. Social class and gender impacting change in bilingual settings: Spanish subject pronoun use in New York. Language in Society 42. 429-452. 
Silva-Corvalán, Carmen. 1982. Subject expression and placement in Mexican-American Spanish. In Jon Amastae \& Lucia Elías-Olivares (eds.), Spanish in the United States: Sociolinguistic aspects, 93-120. Cambridge: Cambridge University Press, pp.

Silva-Corvalán, Carmen. 1994. Language contact and change: Spanish in Los Angeles. Oxford: Clarendon.

Thomason, Sarah G. 2001. Language contact: An introduction. Washington DC: Georgetown University Press.

Toribio, Almeida Jacqueline. 2004. Convergence as an optimization strategy in bilingual speech: Evidence from code-switching. Bilingualism: Language and Cognition 7. 165-173.

Torres Cacoullos, Rena \& Catherine E. Travis. 2010. Variable yo expression in New Mexico: English influence? In Susana Rivera-Mills \& David Villa (eds.), Spanish of the U.S. Southwest: A Language in Transition, 185-206. Madrid: Iberoamericana/Vervuert.

Torres-Cacoullos, Rena \& Catherine E. Travis. 2011. Testing convergence via code-swtiching: Perseveration and the structure of variable subject expression. International Journal of Bilingualism 15(3). 241-267.

Torres-Cacoullos, Rena \& Catherine E. Travis. 2016. Two languages, one effect: Structural priming in spontaneous code-switching. Bilingualism: Language and Cognition 19(4). 733-753.

Travis, Catherine E. 2005. The yo-yo effect: Perseveration in subject expression in Colombian Spanish. In Randall S Gess \& Edward J Rubin (eds.), Theoretical and experimental approaches to Romance linguistics: Selected papers from the 34th Linguistic Symposium on Romance Languages, 329-349. Amsterdam: John Benjamins.

Travis, Catherine E. 2007. Genre effects on subject expression in Spanish: Perseveration in narrative and conversation. Language Variation and Change 19.101-135.

Woolford, Ellen. 1983. Bilingual code-switching and syntactic theory. Linguistic Inquiry 14(5). 520-536.

Zeballos, Andres. 1997. Los Cuentos del Tío Lino. Lima, Peru: Lluvia Editores. 